\title{
Routine follow up after head injury: a second randomised controlled trial
}

\author{
D T Wade, N S King, F J Wenden, S Crawford, F E Caldwell
}

\begin{abstract}
Objective-To confirm that patients admitted to hospital with a head injury benefit from a routinely offered early intervention service.

Patients and methods-A mixed rural and urban Health District of 560000 people with two accident and emergency departments provided the setting. Existing routine services for most patients with head injury are minimal. All patients aged 16-65 years admitted to hospital after a head injury of any severity, with or without other injuries entered the trial. Prospective randomisation, with a block randomisation procedure was used to allocate all eligible patients to either: a group offered an additional service by a specialist team; or a group receiving existing standard services. Patients were assessed at follow up six months after injury. The primary outcome measure was the Rivermead head injury follow up questionnaire, a validated and reliable measure of social disability. The Rivermead post-concussion symptoms questionnaire was used to estimate severity of post-concussion symptoms. Each patient in the trial group was contacted 7-10 days after injury, and offered assessment and interventions as needed. These initially focused on the provision of information, support, and advice. Forty six per cent of patients in the trial group also received further outpatient intervention or additional support by telephone.
\end{abstract}

Results-314 patients were registered: 184 were randomised into the trial group, 130 into the control group. For prognostic data, the groups were comparable at randomisation, and remained comparable when assessed at six months. 132 trial and 86 control patients were followed up at six months after injury. Patients' posttraumatic amnesia ranged from mild $(n=79,40 \%)$, and moderate $(n=62,32 \%)$, to severe $(n=38,19 \%)$ and very severe $(n=17$, 9\%). The trial group patients had significantly less social disability $(p=0.01)$ and significantly less severe post-concussion symptoms $(p=0.02)$ at follow up at six months after injury than the control group patients.

Conclusions-The early interventions offered by a specialist service significantly reduced social morbidity and severity of post-concussion symptoms in trial group patients at six months after head injury. Recommendations about how specialist services should be targeted are made both in the light of these results and those from a previous randomised controlled trial. (f Neurol Neurosurg Psychiatry 1998;65:177-183)

Keywords: head injury; follow up service; randomised controlled trial; outcome

Head injuries are common. Epidemiological studies suggest that between 250 and 300 hospital admissions a year/100 000 of the population in Britain involve a head injury. ${ }^{1}$ Although as few as $7 \%$ of patients may be severely injured, ${ }^{2}$ they have been the focus for services for the head injured. A recent randomised controlled trial of a routine early intervention service for patients with head injury of any severity, suggested that patients with post-traumatic amnesia $\geqslant 1$ hour did benefit in terms of a reduced level of social morbidity. ${ }^{3}$ This second study aimed to confirm and clarify findings from the earlier trial.

Mild and moderate head injuries are usually defined as those resulting in post-traumatic amnesia $<24$ hours, or Glasgow coma scale (GCS) $13-15$, or a loss of consciousness $<30$ minutes, ${ }^{4}$ and account for at least $75 \%$ of all head injuries. ${ }^{5}$ As many as $50 \%$ of patients with such injuries experience a range of postconcussion symptoms which can include headaches, dizziness, fatigue, irritability, reduced concentration, sleep disturbance, memory dysfunction, anxiety and depression, sensitivity to noise or light, and double or blurred vision. ${ }^{67}$ These symptoms usually resolve spontaneously within 3 to 6 months after injury, ${ }^{89}$ although a minority of patients experience symptoms up to and beyond 1 year. ${ }^{10}$ Symptoms, at least initially, may be associated with one or more of the following: diffuse axonal injury, ${ }^{11}$ changes in cerebral blood flow, ${ }^{12}$ minor intracranial lesions seen on MRI, ${ }^{13}$ vestibular damage, ${ }^{9}$ or slowed information processing. ${ }^{14}$ They can be exacerbated or maintained by emotional or cognitive stress, depression, or anxiety (including post-traumatic stress). ${ }^{15-18}$ In the past, research has concentrated on the possible psychological mechanisms involved in postconcussion symptoms, including stress, accident neurosis, and malingering, but more recently organic mechanisms have been demonstrated or implicated using MRI, single photon emission computerised tomography (SPECT), and PET..$^{19}$ Post-concussion symptoms can cause significant psychosocial problems for the patient, both at home and at work, and often coincide with neuropsychological impairments-for example, dysfunction of and in revised form 12

January 1998

Accepted 30 January 1998 
Table 1 Abbreviations used

\begin{tabular}{|c|c|c|}
\hline Abbreviation & Full title & Domain assessed \\
\hline GCS & Glasgow coma scale & Coma; head injury severity \\
\hline HADS & Hospital anxiety and depression scale & Psychological distress \\
\hline IES & Impact of event scale & Psychological severity of accident \\
\hline OXHIS & Oxford head injury service & \\
\hline PCS & Post-concussion symptoms & \\
\hline PTA & Post-traumatic amnesia & Head injury severity \\
\hline RHFUQ & Rivermead head injury follow up questionnaire & Social, functional consequences of head injury \\
\hline RPP & Rivermead PTA protocol & Method of measuring PTA \\
\hline $\mathrm{RPQ}$ & Rivermead post-concussion symptoms questionnaire & Severity of ongoing symptoms \\
\hline SOMC & Short orientation memory concentration test & Current memory, concentration, orientation \\
\hline
\end{tabular}

memory and speed of information processing. ${ }^{1420}$

Managing problems experienced after head injury is not well researched. One controlled unmatched non-randomised study investigated early case management of patients with severe head injury and found that this did not affect outcome. ${ }^{21}$ However, psychological interventions for the less severely injured, including reassurance, information giving, and advice, have been investigated in controlled treatment trials, and findings have indicated that the interventions were associated with significant reductions in the intensity and number of symptoms, and quicker return to work. ${ }^{22} 23$

In 1988 the Medical Disability Society recommended that "every patient attending hospital after head injury should be registered and offered an out-patient appointment". ${ }^{4}$ A recent study investigated the validity of this recommendation, using a large scale randomised control trial to establish whether offering a specialist routine early follow up service to all patients presenting to hospital with a head injury of any severity affected their outcomes six months later. ${ }^{3}$ The results suggested that patients with a head injury resulting in post-traumatic amnesia $\geqslant 1$ hour achieved significantly better outcomes if they had received the service. This finding, however, emerged by post hoc analysis; the population studied included a large proportion of patients with mild injuries $(72 \%$ had post-traumatic amnesia $<1$ hour), and very minor injuries $(48 \%$ without post-traumatic amnesia or loss of consciousness). When data from these patients were included in the analysis, no differences were found between the trial and control groups. A follow up rate for patients at six months of $41 \%$ also made it difficult to draw definitive conclusions from the data.

The study described here tested these findings prospectively by investigating whether a routine specialist early follow up service, offered to patients with non-trivial head injury, affected outcome at 6 months. The service provided and procedures used were virtually identical to those in the previous study, with the difference that patients seen in accident and emergency departments but not admitted to hospital (those most likely to have had only minor or trivial head injuries), were excluded.

\section{Method}

All patients aged between 16 and 65, resident in Oxfordshire (total population 560 000; Health Authority Code QCE), admitted to hospital with a head injury of any severity, and regardless of any additional injuries, were registered using methods described in a previous paper. ${ }^{24} \mathrm{~A}$ head injury was defined as "any blow to the head causing a clinical diagnosis of head injury to be made". The difficulty in defining a head injury has been discussed elsewhere, ${ }^{25}$ and it has been noted previously that many inpatients with a head injury do not have this recorded in their notes. ${ }^{25}$ To register as many patients as possible, a member of the Oxford Head Injury Service (OXHIS) visited the wards two or three times a week. Randomisation into two groups was based on computer generated random numbers with a preference for trial patients (1.5:1). All patients were informed of their inclusion in the study by letter (as required by the ethics committee). Both groups continued to have access to existing hospital services such as the outpatient fracture clinic, but normal clinical services locally do not include routine follow up of patients admitted to hospital after an uncomplicated head injury. The group receiving the early intervention service are referred to as the "trial" group. Those receiving only the existing hospital services and not contacted until 6 months after injury are referred to as the "control" group.

INTERVENTION

Patients randomised to receive the additional service (trial group), were approached at 7 to 10 days after injury, or as soon as possible thereafter. The OXHIS clinicians, a senior nurse therapist, and a senior clinical psychologist, all with experience of working with patients with head injury, aimed to see patients face to face wherever and whenever was most convenient for them. When it was impossible either to contact the patient by telephone, or to see them in person, the service intervention comprised sending the patient an information leaflet about the management of possible symptoms after a head injury. ${ }^{26}$ This was accompanied by a letter with a tear off slip to return if they wished to speak to someone about their head injury.

All those interviewed, either face to face or by telephone, were assessed. Assessment by telephone always included the collection of basic epidemiological data, the administration of the Rivermead post-concussion symptoms questionnaire (RPQ), ${ }^{27}$ and the estimation of the duration of post-traumatic amnesia using the Rivermead post-traumatic amnesia protocol (RPP). ${ }^{28}$ The RPQ lists 16 of the most common post-concussion symptoms, derived from the literature, and asks the patient to rate 


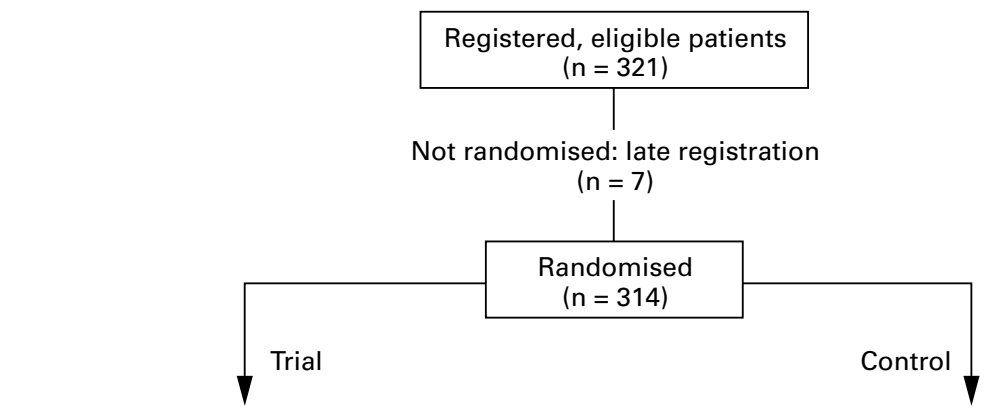

Allocated to receive standard service $(n=130)$

Limited service, died $(n=2)$

Patient contacted OXHIS $(n=6)$

No further contact $(n=44)$

Telephone contact and advice only $(n=19)$

Seen, assessed, advised once only $(n=35)$

Seen, assessed, advised, telephone follow up $(n=62)$

Seen, assessed, advised, outpatient follow up $(n=21)$

Not seen at follow up $(n=52)$

Not contacted: $\operatorname{died}(n=3)$

Moved away, other reasons $(n=5)$

Refused $(n=6)$

Unable to contact ( $n=38$ )

Completed trial, full data $(n=132)$

Flow of patients through RCT.

how problematic, if at all, each symptom has been compared with before their head injury. A reliable and valid total score can be obtained by summing all ratings (except 1, which denotes no change in a symptom). Face to face assessment also included the administration of the impact of event scale (IES), ${ }^{29}$ the hospital anxiety and depression scale (HADS), ${ }^{30}$ and the short orientation memory and concentration test (SOMC, table 1). ${ }^{31}$

After the assessment, trial group patients (and where necessary family members) were given information, advice, and support as

Table 2 Data on age and sex at randomisation

\begin{tabular}{lll}
\hline & Trial $(n=184)$ & Control $(n=130)$ \\
\hline Age $(\mathrm{y}, \mathrm{n}(\%))$ & & \\
$16-19$ & $31(17)$ & $20(15)$ \\
$20-24$ & $33(18)$ & $24(18)$ \\
$25-29$ & $23(12)$ & $17(13)$ \\
$30-34$ & $22(12)$ & $20(15)$ \\
$35-39$ & $22(12)$ & $10(8)$ \\
$40-44$ & $10(5)$ & $12(9)$ \\
$45-49$ & $8(4)$ & $12(9)$ \\
$50-54$ & $12(6)$ & $8(6)$ \\
$55-59$ & $12(6)$ & $7(5)$ \\
$\geqslant 60$ & $11(6)$ & 0 \\
Mean (SD) & $33.53(13.99)$ & $32.45(12.23)$ \\
Sex (n (\%)) & & $102(78)$ \\
M & $130(71)$ & $28(22)$ \\
F & $54(29)$ & \\
\hline
\end{tabular}

\author{
Not seen at follow up $(n=44)$ \\ No service: died $(n=2)$ \\ Moved away, other reasons $(n=2)$ \\ Refused ( $n=4)$ \\ Unable to contact $(n=36)$
}

Completed trial, full data $(\mathrm{n}=86)$

appropriate relating to managing postconcussion symptoms; coping with reduced speed of information processing; likely prognosis and recovery times; how to reduce the effects of cognitive and emotional stress on post-concussion symptoms and vice versa; the nature of, and ways to cope with, posttraumatic stress; and advice on graduated return to normal levels of activity. Information sheets on coping with reduced speed of information processing, post-traumatic stress and memory problems were developed by the OXHIS from the existing literature and used as needed. ${ }^{26}$ (Copies available on request.)

Patients were contacted by telephone or given outpatient appointments to monitor and provide further interventions when required. These included continuing advice, support, counselling, neuropsychological assessment and treatment, cognitive behavioural psychotherapy, and referral to other specialists. The interventions provided by the OXHIS and the potential dangers of offering bland reassurance and general advice without specialist assessment are described in detail elsewhere. ${ }^{19}{ }^{26}$ All trial group patients had open access to the OXHIS and could contact it at any time. Six control group patients also contacted the 
Table 3 Demographic data from patients interviewed at 6 months

\begin{tabular}{|c|c|c|}
\hline & $\begin{array}{l}\text { Trial } \\
(n=132) \\
(n(\%))\end{array}$ & $\begin{array}{l}\text { Control } \\
(n=86) \\
(n(\%))\end{array}$ \\
\hline \multicolumn{3}{|l|}{ Marital status: } \\
\hline Single adult $(\geqslant 18 \mathrm{y})$ & $55(42)$ & $32(37)$ \\
\hline Married, cohabiting & $54(41)$ & $39(45)$ \\
\hline Child $<18$ & $9(7)$ & $6(7)$ \\
\hline Divorced, widowed, separated & $14(11)$ & $9(11)$ \\
\hline \multicolumn{3}{|l|}{ Employment: } \\
\hline In education: child, student & $15(11)$ & $9(11)$ \\
\hline Full time employment & $75(57)$ & $52(61)$ \\
\hline Part time employment & $8(6)$ & $9(11)$ \\
\hline Unemployed - seeking work & $9(7)$ & $3(4)$ \\
\hline Unemployed-not seeking work & $10(8)$ & $6(7)$ \\
\hline Self employed & $8(6)$ & $6(7)$ \\
\hline Retired & $1(1)$ & $0(0)$ \\
\hline Other & $5(4)$ & $1(1)$ \\
\hline Missing data & $1(1)$ & $0(0)$ \\
\hline \multicolumn{3}{|l|}{ Accident type: } \\
\hline $\begin{array}{l}\text { Road traffic accident, including } \\
\text { pedestrian }\end{array}$ & $54(41)$ & $36(42)$ \\
\hline Cyclist & $13(10)$ & $8(9)$ \\
\hline Horse riding & $3(2)$ & $4(5)$ \\
\hline Domestic accident & $9(7)$ & $8(9)$ \\
\hline Work accident & $10(8)$ & $5(6)$ \\
\hline Assault & $16(12)$ & $10(12)$ \\
\hline Sport & $7(5)$ & $4(5)$ \\
\hline Other & $20(15)$ & $11(13)$ \\
\hline \multicolumn{3}{|c|}{$\begin{array}{l}\text { Post-traumatic amnesia (PTA) as estimated at } 6 \text { month follow } \\
\text { up: }\end{array}$} \\
\hline$<1 \mathrm{~h}$ & $48(41)$ & $31(40)$ \\
\hline$\geqslant 1 \mathrm{~h}<24 \mathrm{~h}$ & 39 (33) & $23(29)$ \\
\hline$\geqslant 24 \leqslant 7$ days & $21(18)$ & $17(22)$ \\
\hline$>7$ days & $10(8)$ & $7(9)$ \\
\hline Unable to estimate & 14 & 8 \\
\hline
\end{tabular}

service (after receipt of the letter notifying them of the study). They were assessed and offered treatment.

\section{FOLLOW UP}

At six months after injury all randomised patients were contacted, initially by letter and then by telephone, to ask whether they were willing to be followed up. The assessors were independent of the initial service provision and blind to the randomisation. Patients were seen face to face at home or as outpatients whenever possible, but to increase the follow up rate, they were also interviewed over the telephone if necessary. Every effort was made to contact as many patients as possible, including repeated telephone calls and second letters.

At the follow up assessment, data were collected on demographic details (age, sex, marital status, employment status, etc) and details of the injury (cause, associated injuries,

Table 4 Frequency of reported changes in work, relations, social, and leisure activities at six months

\begin{tabular}{lll}
\hline & Trial & Control \\
\hline Item (n (\%)) & $27(21)$ & $24(28)$ \\
Participating in conversation with one & $31(24)$ & $27(31)$ \\
Participating in conversation with $\geqslant 2$ & $19(14)$ & $20(23)$ \\
Performing routine domestic activities & $23(17)$ & $30(35)$ \\
Participating in previous social activities & $27(21)$ & $28(33)$ \\
Participating in previous leisure activities & $23(17)$ & $21(24)$ \\
Maintaining previous work load & $34(26)$ & $27(31)$ \\
Finding work more tiring & $19(14)$ & $16(19)$ \\
Relationships with your friends & $15(11)$ & $19(22)$ \\
Relationship with your partner & $14(11)$ & $22(26)$ \\
Ability to cope with family demands & & \\
RHFUQ sum total ratings (n (\%)): & $58(44)$ & $28(52)$ \\
0 & $45(34)$ & $28(32)$ \\
1-10 & $21(16)$ & $17(20)$ \\
$11-20$ & $6(4)$ & $12(14)$ \\
$21-30$ & $2(1)$ & $1(1)$ \\
31-40 & $5.36(7.81)$ & $8.23(8.75)$ \\
\hline
\end{tabular}

etc). Specific clinical assessments included the duration of post-traumatic amnesia using the Rivermead post-traumatic amnesia protocol $(\mathrm{RPP})^{28}$; the Rivermead postconcussion symptoms questionnaire (RPQ) ${ }^{27}$; and the Rivermead head injury follow-up questionnaire (RHFUQ). ${ }^{32}$ The RHFUQ lists 10 aspects of everyday life commonly affected by an appreciable, but not necessarily severe, head injury. The patient rates the degree to which their experience of each item has changed since their injury. A reliable and valid total score can be obtained by summing the ratings on all items.

\section{ANALYSIS}

The data have been analysed primarily according to the group allocation (an "intention to treat" analysis), but subgroup analysis has investigated the effect of the six control group patients who received the early intervention service. Statistical tests used to compare groups were primarily for non-parametric data and comprised the $\chi^{2}$ test and the MannWhitney $U$ test, with two tailed p values. Ethical approval for the study was obtained. The first study suggested that 200 patients should be included to detect a difference.

\section{Results}

Three hundred and fourteen patients were randomised: 184 to receive the additional intervention (the "trial" group) and 130 to receive only existing standard services (the "control" group). The figure shows the flow of patients in the trial. Seven patients were excluded because they were notified to the head injury register more than six weeks after injury. At six month follow up 218 (69\%) randomised patients were interviewed, $132(71 \%)$ from the trial group, $86(66 \%)$ from the control group. There was no evidence of selective follow up of either group $\left(\chi^{2}=0.23\right)$. The groups were comparable for age and sex at randomisation (table 2).

Statistical tests on data collected at six month follow up relating to the accident itself and the patient's premorbid social situation indicated no significant differences $(p<0.05)$ between the trial and control groups for age, sex, marital status, employment situation, cause of injury, or associated injuries sustained or severity of head injury as measured by posttraumatic amnesia (table 3).

At six months, the trial group's totalled ratings on the RHFUQ ${ }^{32}$ were significantly lower than those of the control group (MannWhitney $U$ test: $z=-2.54 ; \mathrm{p}=0.01$ ), indicating that the trial group patients experienced less disruption of social activities. Table 4 shows the frequencies of specific disabilities reported and the range of ratings.

The trial group also had significantly lower ratings than the control group on the $\mathrm{RPQ}^{27}$ (Mann-Whitney $U$ test: $z=-2.27 ; \mathrm{p}=0.02$ ), indicating that the trial group patients experienced fewer or less severe post-concussion symptoms. Table 5 shows the frequency of specific reported symptoms and range of totalled ratings. 
Table 5 Patients reporting symptoms after concussion at 6 month follow up

\begin{tabular}{lll}
\hline Symptoms $(n(\%))$ & Trial & Control \\
\hline Headache & $34(26)$ & $33(38)$ \\
Nausea, vomiting & $12(9)$ & $15(17)$ \\
Dizziness & $30(23)$ & $22(26)$ \\
Noise sensitivity & $34(26)$ & $25(29)$ \\
Sleep disturbance & $26(20)$ & $28(33)$ \\
Fatigue & $47(36)$ & $46(54)$ \\
Irritability & $38(29)$ & $36(42)$ \\
Feeling depressed & $33(25)$ & $29(34)$ \\
Feeling frustrated & $37(28)$ & $37(43)$ \\
Poor memory & $50(38)$ & $36(42)$ \\
Poor concentration & $30(23)$ & $31(36)$ \\
Taking longer to think & $34(26)$ & $30(35)$ \\
Blurred vision & $12(9)$ & $16(19)$ \\
Sensitivity to light & $20(15)$ & $20(23)$ \\
Double vision & $3(2)$ & $4(5)$ \\
Restlessness & $29(22)$ & $21(24)$ \\
RPQ sum total ratings & & \\
$\quad 0+1$ & $39(30)$ & $21(24)$ \\
2-10 & $50(38)$ & $18(21)$ \\
$11-20$ & $17(13)$ & $23(27)$ \\
$21-30$ & $16(12)$ & $10(11)$ \\
$31-40$ & $7(5)$ & $10(11)$ \\
$41-64$ & $3(2)$ & $5(7)$ \\
Mean (SD) & $9.8(11.7)$ & $13.9(13.6)$ \\
& &
\end{tabular}

Table 6 shows subgroup analysis of the totalled ratings on the RHFUQ and RPQ for the control and trial groups, each divided according to severity of head injury (as measured by post-traumatic amnesia). When patients were classified using traditional criteria into mild, moderate, severe, or very severe groups $^{28}$ the main benefit appeared in the mild and moderate groups. When different cut off points for post-traumatic amnesia were used, patients with post-traumatic amnesia $<7$ days seemed to benefit most from the early intervention service, at least for better social outcomes.

Six of the patients interviewed at 6 months had been randomised to the control group but had received the early intervention. All these patients had significant scores on the RHFUQ (median $=12$, range 8-21) or RPQ (median $=20$, range $2-33$ ), and all but one had post-traumatic amnesia $\leqslant 24$ hours. They were almost certainly a self selected group of patients with appreciable problems who had asked to receive a service. When they were excluded from analyses, Mann-Whitney test results remained significant for both RHFUQ

Table 6 Subgroup analysis of RHFUQ and RPQ Mann-Whitney scores at 6 months follow up

\begin{tabular}{|c|c|c|c|c|c|c|c|}
\hline & \multirow[b]{2}{*}{ Trial } & \multirow[b]{2}{*}{ Control } & \multirow[b]{2}{*}{ Total } & \multicolumn{2}{|l|}{$R H F U Q$} & \multicolumn{2}{|l|}{$R P Q$} \\
\hline & & & & z Score & $p$ Value & z Score & $p$ Value \\
\hline \multicolumn{8}{|l|}{ PTA class ${ }^{\star}$} \\
\hline Mild & & & & & & & \\
\hline $\begin{array}{l}\text { PTA }<1 \mathrm{hr} \\
\text { Moderate }\end{array}$ & 48 & 31 & 79 & -2.29 & 0.02 & -1.78 & 0.07 \\
\hline $\begin{array}{l}\text { PTA } \geqslant 1 h<24 h \\
\text { Severe }\end{array}$ & 39 & 23 & 62 & -1.75 & 0.08 & -0.63 & 0.53 \\
\hline $\begin{array}{l}\text { PTA } \geqslant 24 h \leqslant 7 \text { days } \\
\text { Very severe }\end{array}$ & 21 & 17 & 38 & -2.81 & 0.72 & -0.13 & 0.89 \\
\hline PTA $>7$ days & 10 & 7 & 17 & -0.05 & 0.96 & -0.20 & 0.84 \\
\hline \multicolumn{8}{|l|}{ PTA subgroups ${ }^{\star}$ : } \\
\hline $\mathrm{PTA}=0$ & 27 & 14 & 41 & -2.57 & 0.01 & -1.88 & 0.06 \\
\hline PTA $<1 \mathrm{~h}$ & 48 & 31 & 79 & -2.29 & 0.02 & -1.78 & 0.07 \\
\hline $\mathrm{PTA} \geqslant 1 \mathrm{~h}$ & 70 & 47 & 117 & -1.36 & 0.17 & -0.45 & 0.65 \\
\hline PTA $<24 \mathrm{~h}$ & 87 & 54 & 141 & -2.81 & 0.005 & -1.88 & 0.06 \\
\hline $\mathrm{PTA} \geqslant 24 \mathrm{~h}$ & 31 & 24 & 55 & -0.145 & 0.88 & -0.01 & 0.99 \\
\hline PTA $\leqslant 7$ days & 108 & 71 & 179 & -2.59 & 0.01 & -1.80 & 0.07 \\
\hline PTA >7 days & 10 & 7 & 17 & -0.05 & 0.96 & -0.20 & 0.84 \\
\hline
\end{tabular}

^PTA data for 22 patients were unassessable. scores $(z=-2.04, \mathrm{p}=0.04)$ and RPQ scores $(z=-1.92, \mathrm{p}=0.05)$.

The intervention given to all trial group patients included written information and advice about coping with head injury. After attempts to contact them by telephone or letter, $44(24 \%)$ did not respond and proved impossible to contact. Nineteen (10\%) were contacted and given advice over the telephone, $35(19 \%)$ were assessed face to face, $62(34 \%)$ were assessed face to face and required additional telephone support, and $21(12 \%)$ were assessed face to face and required further outpatient contact. Of those 52 trial group patients who were not interviewed at six month follow up, all had been given or sent written information: 29 (56\%) had not responded to the invitation to contact the service, three $(6 \%)$ were contacted and given advice over the telephone, six $(11 \%)$ had had face to face contact, $10(19 \%)$ were assessed face to face and required additional telephone support, and four $(8 \%)$ were assessed face to face and required additional out patient contact. The six control group patients who had contacted the service for help were given written information and two were seen once, two needed additional telephone contact, and two additional face to face contact. Three patients randomised to the trial group died before the service could contact them and two patients in the control group died before the six month follow up assessment.

The assessing clinicians guessed whether or not patients had received a service and were $61 \%$ successful $\left(\mathrm{X}^{2}=23.92\right)$ which is at greater than chance levels. This was mainly because a large proportion of control patients told the clinicians that they had not received any intervention before their assessments were completed.

\section{Discussion}

The results of this large randomised controlled trial indicate that patients who received specialist intervention after head injury had significantly less social disability and significantly less severe post-concussion symptoms six months after injury $(p<0.05)$, compared with those who did not receive the service.

The problems of defining and registering patients with head injury have been discussed previously in relation to the earlier randomised controlled trial. ${ }^{24}$ There is no agreed single diagnostic criterion: not all patients even attend hospital and the diagnosis may be missed. It is inevitable that not all patients will have been registered and some clinicians might not agree on the diagnosis in every case. Moreover, it is possible that patients who had had severe injuries and were considered likely to die were not notified. However, all patients surviving a severe head injury would have been registered because team members visited the ward every week. The number of patients in the age range studied was that anticipated and we think that the patients randomised were representative of patients admitted to and discharged alive from most trauma wards with head injury. 
Baseline information collected at the time of admission was minimal as there was no routine assessment at the time of notification to randomisation. Practical considerations such as staff resources available and the difficulty in tracing and contacting such a large number of people, many of whom were well, made it impossible to undertake a formal assessment within the first few days. Furthermore, the process of contacting and interviewing all randomised patients would probably have been therapeutic, as providing information and reassurance would have been unavoidable, affecting data from the control group. Data in hospital records are often unreliable and incomplete. The main prognostic factor, post-traumatic amnesia, was assessed at six months after injury in all patients interviewed and this has been shown to be valid and reliable. ${ }^{28}$ The randomisation process was successful (tables 2 and 3) in that there were no significant epidemiological differences between trial and control groups $(\mathrm{p}<0.05)$. We have no reason to doubt that the groups were comparable.

The percentage of patients followed up $(69 \%)$ was better in this study than in the previous randomised control trial, ${ }^{3}$ and was good for this particular population of patients. A more complete follow up would be extremely difficult to achieve in a group of patients who often may have recovered fully, most of whom who work, and for whom there is no obvious incentive to cooperate with researchers. The information needed to get in touch with younger patients is often unavailable. For some patients, their head injuries may have arisen in traumatic circumstances which they do not wish to discuss. We have no reason to think that follow up was biased towards either group. It is likely that most of those patients not interviewed at 6 months had few symptoms. The clinicians undertaking the 6 month follow up had not been involved in giving treatment and we think that the follow up data collected were not biased.

The outcome measures used were those already tested for reliability and validity in this type of research. ${ }^{3}$ We did not use any specific tests of cognitive function. This would have reduced the follow up rate significantly (they cannot be done quickly or by telephone). Moreover, from the perspective of the patient it is their symptomatology and disability that concerns them. The lack of data on cognitive skills does make it more difficult to understand how the intervention helped patients, but does not reduce the validity of the findings.

Two possible reasons why an overall benefit to the trial group patients was shown in the present study but not the previous randomised control trial $^{3}$ suggest themselves. The earlier study included a large proportion of patients with no post-traumatic amnesia (48\%), or, with post-traumatic amnesia<1 hour $(72 \%)$, who had no social disability and no postconcussion symptoms at six month follow up (57\% and $43 \%$ respectively). In the present study, only $40 \%$ of patients had post-traumatic amnesia $<1$ hour, only $39 \%$ had no disability at follow up, and only $28 \%$ had no post- concussion symptoms at follow up (tables 4 and 5). The present study was influenced far less, therefore, by the "flooring" effects of large numbers of trivial head injuries. Secondly, more patients in the present study received additional intervention rather than information alone: $33 \%$ had extra telephone support and $12 \%$ outpatient intervention, compared with $13 \%$ and $6 \%$ respectively in the first randomised control trial

Tables 4 and 5 can be used to estimate the practical benefits arising from the service. Table 4 suggests that the most common social disabilities to be benefited by intervention included relationship with partner, coping with family demands, ability to participate in social activities, and, ability to enjoy leisure activities. Table 5 suggests that the most common post-concussion symptoms to be reduced by intervention included concentration difficulties, headaches, fatigue, sleep disturbance, irritability; and, frustration. The mean totalled ratings for the control and trial groups were 8 and 5 respectively on the RHFUQ, and 14 and 10 respectively on the RPQ.

This suggests that the social disabilities which a representative control group patient might experience at six months could include moderate problems in their relationship with their partner, moderate problems in enjoying leisure activities, and mild problems coping with family demands. A comparable trial group patient might only experience moderate problems in enjoying leisure activities. Similarly, the post-concussion symptoms of a representative control group patient could include severe problems with concentration and fatigue, and moderate problems with irritability and headache. A comparable trial group patient might experience only mild problems with fatigue and concentration, and moderate problems with irritability and headache. The results suggest that the intervention helped patients significantly in coping with social disability, probably by encouraging the use of better compensatory strategies. They also show that the intervention reduced the severity of postconcussion symptoms, probably by minimising the effects of a vicious cycle of anxiety exacerbating post-concussion symptoms and vice versa.

Tables 4 and 5, however, also show that at 6 months after injury a significant number of patients continued to experience some social disability $(61 \%)$ and post-concussion symptoms $(72 \%)$. This highlights the danger of giving bland reassurance which can cause anger and frustration in patients if their symptoms and disabilities do in fact persist. ${ }^{19}$

Table 6 shows the subgroup analysis suggesting that the patients who benefited the most from the intervention were those whose post-traumatic amnesia was $<7$ days. Those with post-traumatic amnesia $\geqslant 7$ days appeared not to benefit. The importance of these findings are difficult to assess because the number of very severely injured patients was small, although explanations do suggest themselves. Firstly, it is possible that a ceiling effect arose from the last group as the outcome 
measures were not designed for patients with very severe injuries. Such patients often have quantitatively and qualitatively different problems from those whose injuries were less severe. Secondly, the more severely injured patients (who are likely to have remained in hospital many months, and often transferred to a specialist centre and received rehabilitation) may not have benefited from the service the input of which was more appropriate for patients well enough to be discharged home and no longer in post-traumatic amnesia. This finding is consistent with the lack of influence seen in the study of case management. ${ }^{21}$ Thirdly, it is possible that benefits for this group of patients might not be evident as early as six months after injury.

In summary, the results suggest that all patients with head injury with post-traumatic amnesia $<7$ days would benefit from routine early intervention by a specialist service if their head injuries or other injuries are sufficiently serious for them to be admitted to hospital. A previous study suggested that patients experiencing significant post-concussion symptoms, or increased anxiety, or significant depression, or evidence of post-traumatic stress, early after injury, were those most likely to experience persisting post-concussion symptoms later on. ${ }^{33}$ They would probably also benefit from routine early intervention, as would all patients with post-traumatic amnesia $\geqslant 1$ hour who attend accident and emergency departments only and are not admitted to hospital. ${ }^{3}$

The Medical Disability Society's recommendation that all patients with head injury should be followed up routinely requires modification. On the evidence of these results we recommend that all patients admitted to trauma wards with a head injury should be offered early specialist follow up services routinely, as should any patient with posttraumatic amnesia $\geqslant 1$ hour who attends an accident and emergency department. Specialist services should also be available to patients attending an accident and emergency departments or consulting their general practitioner who report appreciable post-concussion symptoms symptoms, depression, anxiety or posttraumatic stress within a few weeks of their injury, regardless of their post-traumatic amnesia.

We thank Mrs Ann White for all her help with this project (maintaining the register, undertaking randomisation, typing letters and papers etc); the Department of Health for funding the Oxford Head Injury Service as part of their traumatic brain the Oxford Head Injury Service as part of their traumatic brain injury initiative; the Rivermead specialty team budget for addi-
tional funding; the staff on all the trauma wards and in the accitional funding; the staff on all the trauma wards and in the accident and emergency departments for all their help and supp
and the patients and their families for their cooperation.

1 Jennett B, MacMillan R. Epidemiology of head injury. BMF 1981;282:101-4.

2 Artiola I, Fortuny L, Briggs M, et al. Measuring the duration of post-traumatic amnesia. $\mathcal{F}$ Neurol Neurosurg Psychiatry 1980;43:77-379.
3 Wade DT, Crawford S, Wenden FJ, et al. Does routine follow up after head injury help? A randomised controlled low up after head injury help? A randomised cont
trial. $\mathcal{F}$ Neurol Neurosurg Psychiatry 1997;62:478-84.

4 Medical Disability Society. The management of traumatic brain injury. London: The Medical Disability Society, 1988.

5 Kraus JF, Nourjah P. The epidemiology of mild uncomplicated brain injury. Trauma 1988;28:1637-43.

6 Mandel S. Minor head injury may not be minor. Postgrad Med 1989;85:213-25.

7 Binder LM. Persisting symptoms after mild head injury. A review of the postconcussive syndrome. F Clin Exp Neuropsychol 1986;8:323-46.

8 Alves WM, Colohan ART, O'Leary TJ, et al. Understanding post traumatic symptoms after minor head injury. fournal of Head Trauma Rehabilitation 1986;1:1-12.

9 Evans RW. The post concussion syndrome and the sequelae of mild head injury. Neurol Clin 1992;10:815-47.

10 Rutherford WH, Merrett JD, McDonald JR. Symptoms at one year following concussion from minor head injuries. Injury 1979;10:225-30.

11 Oppenheimer DR. Microscopic lesions in the brain following head injury. F Neurol Neurosurg Psychiatry 1968;31:299306.

12 Varney NR, Bushnell DL, Nathan M, et al. NeuroSPECT correlates of disabling mild head injury: preliminary correlates of disabling mild head injury: preliminary finding

13 Levin H, Williams DH, Eisenberg HM, et al. Serial MRI and neurobehavioural findings after mild to moderate head injury. $\mathcal{F}$ Neurol Neurosurg Psychiatry 1992;55:255-62.

14 Gronwall D, Wrightson P. Delayed recovery in intellectual function after mild head injury. Lancet 1974;ii:605-9.

15 Moss NEG, Crawford S, Wade D T. Post concussion symptoms-is stress a mediating factor? Clinical Rehabilitation $1994 ; 8: 149-56$.

16 Ewing R, McCarthy D, Gronwall D, et al. Persisting effects of minor head injury observable during hypoxic stress. $\mathcal{F}$ Clin Neuropsychol 1980;2:147-55.

17 Lishman A. Physiogenesis and psychogenesis in the Lishman A. Physiogenesis and psychogenesis in the
post-concussional syndrome. Br f Psychiatry 1988;153: post-co

18 King NS. Post traumatic stress disorder and head injury as a dual diagnosis: 'islands' of memory as a mechanism. F Neurol Neurosurg Psychiatry 1997;62:82-4.

19 King NS. Mild head injury: neuropathology, sequelae, measurement and recovery. Br f Clin Psychol 1997;36:16184.

20 Dikmen S, Temkin N, Armsden A. Neuropsychological recovery; the relationship to psychosocial functioning and post concussional complaints. In: Levin H, Eisenberg HM, Benton AL, eds. Mild head injury. New York: Oxford University Press, 1989.

21 Greenwood RJ, McMillan TM, Brooks DN, et al. Effects of case management after severe head injury. BMF 1992;308: $1199-205$.

22 Minderhoud JM, Boelens MEM, Huizenga J, et al. Treatment of minor head injuries. Clin Neurol Neurosurg 1980;82:127-40.

23 Relander M, Troupp H, Bjorkesten af G. Controlled trial of treatment for cerebral concussion. BMF 1972;4:777-9.

24 Moss NEG, Powers D, Wade DT. The Oxford head injury register. Disabil Rehabil 1996;18:169-73.

25 Moss NEG, Wade DT. Admissions after head injury: how many occur and how many are recorded? Injury 1996;27: $159-61$

26 King NS, Crawford S, Wenden FJ, et al. Interventions and service need following mild and moderate head injury: the Oxford Head Injury Service. Clinical Rehabilitation 1997; 11:13-27.

27 King N S, Crawford S, Wenden F J, et al. The Rivermead post concussion symptoms questionnaire: a measure of post concussion symptoms questionnaire: a measure of symptoms commonly experienced after

28 King NS, Crawford S, Wenden FJ, et al. Measurement of post-traumatic amnesia: how reliable is it? $\mathcal{F}$ Neurol Neurosurg Psychiatry 1997;62:38-42.

29 Horowitz M, Wilner N, Alvarez W. Impact of event scale: a measure of subjective distress. Psychsom Med 1979;41:20918.

30 Zigmund AS, Snaith RP. Hospital anxiety and depression scale. Acta Psychiatr Scand 1983;67:361-70.

31 Katzman R, Brown C, Fuld P, et al. Validation of a short orientation memory concentration test of cognitive impairment. Am F Psychiatry 1983;140:737-9

32 Crawford S, Wenden F, Wade DT. The Rivermead head injury follow up questionnaire: a study of a new rating scale and other measures to evaluate outcomes after head injury. f Neurol Neurosurg Psychiatry 1996;60:510-4.

33 King NS. Emotional, neuropsychological and organic factors: their use in the prediction of persisting postconcussion symptoms after moderate and mild head injuries. $\mathcal{f}$ Neurol Neurosurg Psychiatry 1996;61:75-81. 